\title{
Group II intron and repeat-rich red algal mitochondrial genomes demonstrate the dynamic recent history of autocatalytic RNAs
}

Dongseok Kim, JunMo Lee ${ }^{2}$, Chung Hyun Cho ${ }^{1}$, Eun Jeung Kim', Debashish Bhattacharya ${ }^{3}$ and Hwan Su Yoon ${ }^{1 *}$ (D)

\begin{abstract}
Background: Group II introns are mobile genetic elements that can insert at specific target sequences, however, their origins are often challenging to reconstruct because of rapid sequence decay following invasion and spread into different sites. To advance understanding of group II intron spread, we studied the intron-rich mitochondrial genome (mitogenome) in the unicellular red alga, Porphyridium.

Results: Analysis of mitogenomes in three closely related species in this genus revealed they were 3-6-fold larger in size (56-132 kbp) than in other red algae, that have genomes of size $21-43 \mathrm{kbp}$. This discrepancy is explained by two factors, group II intron invasion and expansion of repeated sequences in large intergenic regions. Phylogenetic analysis demonstrates that many mitogenome group II intron families are specific to Porphyridium, whereas others are closely related to sequences in fungi and in the red alga-derived plastids of stramenopiles. Network analysis of intron-encoded proteins (IEPs) shows a clear link between plastid and mitochondrial IEPs in distantly related species, with both groups associated with prokaryotic sequences.

Conclusion: Our analysis of group II introns in Porphyridium mitogenomes demonstrates the dynamic nature of group II intron evolution, strongly supports the lateral movement of group II introns among diverse eukaryotes, and reveals their ability to proliferate, once integrated in mitochondrial DNA.
\end{abstract}

Keywords: Genome expansion, Group II introns, Repeated sequences, Horizontal gene transfer, Red algae

\section{Background}

Group II introns are widely distributed in the organelle genomes of plants, fungi, algae, and protists, and also invade the genomes of bacteria and viruses [1,2]. Because group II introns are mobile genetic elements that have the ability to insert at specific target sequences [3], homologous group II introns have spread into the same site

\footnotetext{
* Correspondence: hsyoon2011@skku.edu

'Department of Biological Sciences, Sungkyunkwan University, Suwon 16419, South Korea

Full list of author information is available at the end of the article
}

in organelle genomes of distantly related species [1]. Despite knowledge of the mechanisms of spread, group II intron origins are often challenging to study because of rapid sequence decay following invasion and spread into different sites [4]. To this end, conserved group II intron-encoded proteins (IEPs) have been widely used to trace their origins $[5,6]$. Generally, group II intron IEPs consist of four sequence domains encoding reverse transcriptase (RT), maturase (X), DNA binding (D), and DNA endonuclease (En) functions [7]. Domains such as RT and D are usually essential for retro-transposition,

(c) The Author(s). 2021 Open Access This article is licensed under a Creative Commons Attribution 4.0 International License, which permits use, sharing, adaptation, distribution and reproduction in any medium or format, as long as you give appropriate credit to the original author(s) and the source, provide a link to the Creative Commons licence, and indicate if changes were made. The images or other third party material in this article are included in the article's Creative Commons licence, unless indicated otherwise in a credit line to the material. If material is not included in the article's Creative Commons licence and your intended use is not permitted by statutory regulation or exceeds the permitted use, you will need to obtain permission directly from the copyright holder. To view a copy of this licence, visit http://creativecommons.org/licenses/by/4.0/ The Creative Commons Public Domain Dedication waiver (http://creativecommons.org/publicdomain/zero/1.0/) applies to the data made available in this article, unless otherwise stated in a credit line to the data. 
but they are not necessary for splicing. Therefore, mutations in RT and D post-invasion have little effect on the host, and some group II introns can survive for extended periods, in particular, if the splicing process is co-opted by the host to regulate gene expression or other functions [8].

The life-cycle of group II introns comprises three wellcharacterized phases [9]: invasion of the target site, sequence drift/divergence, and deletion. Post-deletion, empty target sites may be invaded by other cognate introns and this cycle can repeat itself. The phylogenetic distribution of mobile group II introns suggests that they have originated from bacteria and were transferred to eukaryotes via the two primary endosymbioses that led to the origins of mitochondria and plastids $[6,10]$. This idea is supported by the presence of IEP-containing group II introns in most bacterial genomes that act as retroelements with functional ribozyme and RT components [11]. In contrast, organelle group II introns often lack open reading frames (ORFs) and/or contain degenerate IEPs or RNA structures [7, 12]. Although unproven, group II introns are considered the ancestors of spliceosomal introns found in many eukaryotes, including humans. This idea is supported by the common splicing mechanism and structural similarity between group II introns and small nuclear RNA (snRNA)/intron/exon pairing that comprises the spliceosome during the splicing reaction. Group II introns are also associated with nuclear non-long terminal repeat (LTR) retroelements. In fact, RTs of non-LTR elements are phylogenetically closely related to IEPs in group II introns $[1,6]$. Group II introns are believed to have existed in the nuclear genome of early eukaryotes. Their disappearance may be explained by RNA instability and effects on translation, or the possibility that they were coopted to give rise to canonical spliceosomal introns [13].

The Porphyridiophyceae is a mesophilic unicellular red algal class, which inhabits sites with varying salinity including freshwater, brackish water, and seawater. These red algal taxa contain many sulfated cell wall polysaccharides as antioxidants to provide protection against reactive oxygen species (ROS) [14]. The nuclear genome of Porphyridium purpureum CCMP1328 has been used as a model to study horizontal gene transfer (HGT) and phycobilisome evolution $[15,16]$. The plastid genome of $P$. purpureum CCMP1328 contains an exceptionally high number of introns (43 introns - one group I and 42 group II introns) with unusual twintrons [17-19]. However, Porphyridium mitochondrial genomes (hereafter, mitogenomes) have not yet been studied. To advance understanding of autocatalytic RNA evolution, we generated mitogenomes from three Porphyridium isolates: P. purpureum CCMP1328, $P$. purpureum SAG1380-1a, and $P$. aerugineum CCMP1948. Because these mitogenomes are unusually large in size, we focused on the role of group II introns and repeats in mitogenome growth.

\section{Results and discussion}

\section{General features of Porphyridium mitogenomes}

The complete circular mitogenome sequences of $P$. purpureum CCMP1328 (MT483996), P. purpureum SAG1380-1a (MT483997), and $P$. aerugineum CCMP1948 (MT483995) show significant size variation (132 kbp, $129 \mathrm{kbp}$, and 56 $\mathrm{kbp}$, respectively). These mitogenomes are 3-fold larger in size than any of the 81 currently available red algal mitogenomes that are 21 43 kb in size (Fig. 1a and Additional file 2: Table S1). Bangia fuscopurpurea (NC_026905, Bangiophyceae), the previously largest reported mitogenome $(43,517$ bp), includes two tandem repeats and five introns (two in the large subunit rRNA gene and three in the cox1 gene). The Porphyridium mitogenomes, however, encode fewer protein coding genes (i.e., 13-14 CDS) than other red algae (i.e., 16$28 \mathrm{CDS}$ ), containing two subunits of the ATP synthase complex (atp6 and atp9), one subunit of cytochrome-b (cob), three subunits of cytochrome-c oxidase ( $\operatorname{cox} 1, \operatorname{cox} 2$, and cox3), and seven subunits of NADH dehydrogenase (nad1, nad2, nad3, nad4, nad4L, nad5, and nad6). There is one partial small ribosomal subunit (rps3) in $P$. aerugineum CCMP1948 (Additional file 2: Table S2). With two ribosomal RNAs (rnl and rns), P. purpureum CCMP1328, P. purpureum SAG1380-1a, and $P$. aerugineum CCMP1948 contain 13,13 , and 9 tRNA genes, respectively. In contrast, these genomes have a high intron content (i.e., 46,46 , and 9 introns) with 14, 14, and 5 IEPs in P. purpureum CCMP1328, P. purpureum SAG1380-1a, and $P$. aerugineum CCMP1948, respectively, that explain the increase in genome size (Fig. 1).

Correlation analysis shows that introns $\left(r^{2}=0.992\right)$ and intergenic regions $\left(r^{2}=0.967\right)$ are major factors in genome size expansion (Additional file 1: Fig. S1a). In fact, introns in these three taxa account for 86.3\%, $86.1 \%$, and $56.8 \%$ of the total genic region, respectively. As an example, the cob gene of $P$. purpureum CCMP1328 is $20,224 \mathrm{bp}$ in size including $1150 \mathrm{bp}$ of exon and 19,074 bp (94.3\%) of intron sequences (Additional file 2: Table S3). The intergenic regions between CDSs (including ORFs) also comprise a large proportion (27 36\%) of the total length of mitogenomes. Based on correlation analysis, two major contributors to mitogenome expansion are a total of $74 \mathrm{kbp}$ (56\% of mitogenome size) of intron sequences including 14 IEPs and 66 tandem repeats concentrated in the large intergenic region (LIR: $23 \mathrm{kbp}, 17 \%)$ of $P$. purpureum CCMP1328. Likewise, the mitogenome of $P$. aerugineum CCMP1948 has $17 \mathrm{kbp}$ (30\% of mitogenome size) of introns including five group II IEPs and 47 tandem repeats in the LIR (LIR: $12 \mathrm{kbp}, 21 \%$ ). This massive expansion in mitogenome size has also been reported in the alpine soil green alga Chlorokybus atmophyticus (201,763 bp). It is interesting to note that the $C$. atmophyticus mitogenome also includes a large number of introns (i.e., six group I introns and 14 group II introns), 249 tandem repeats, and 


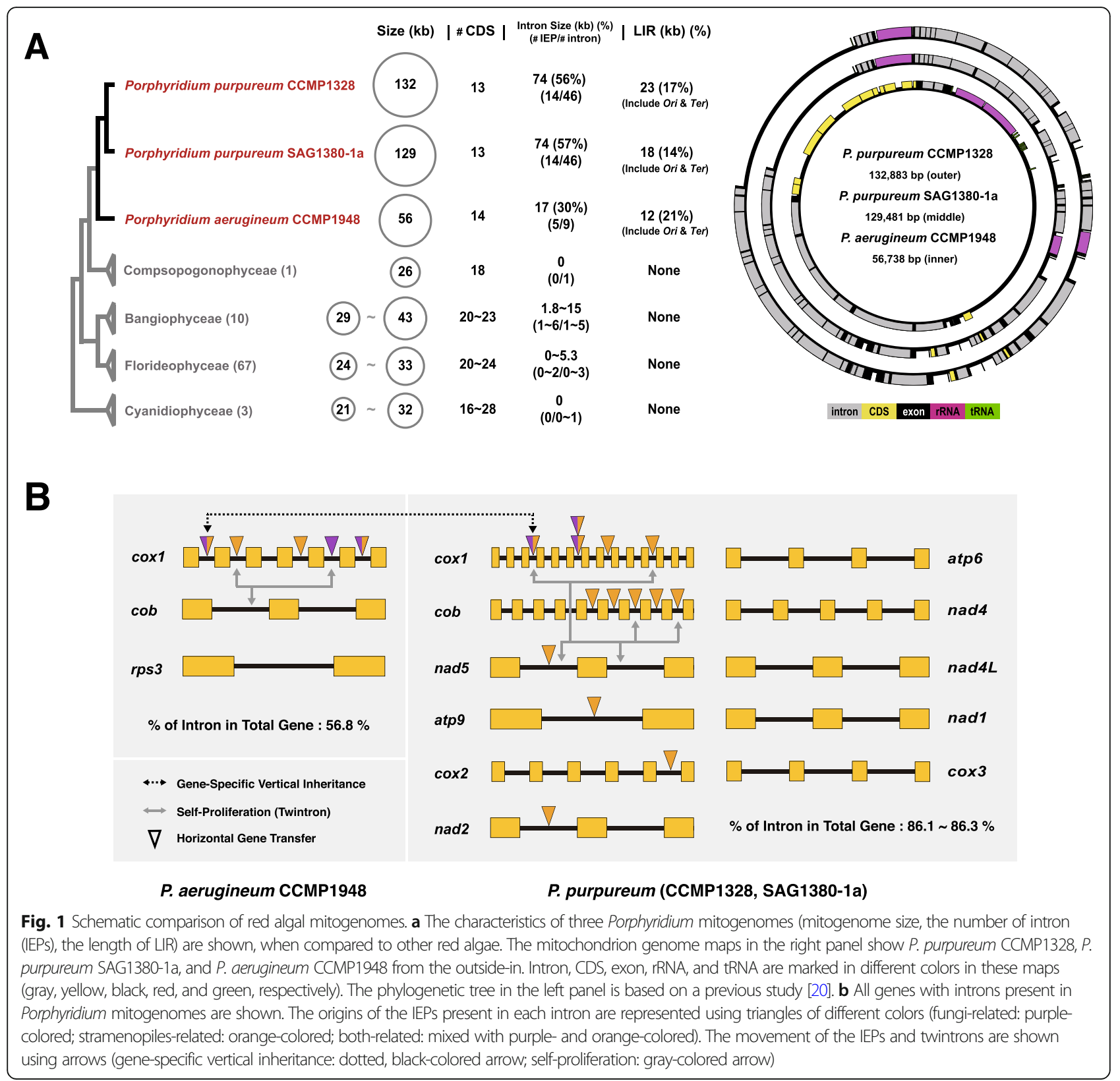

extended intergenic regions rich in repeated elements. Interestingly, 10 group II introns in the C. atmophyticus mitogenome are located in tRNA genes [21]. Therefore, introns (30-56\%) and LIRs (17-21\%) including many repeats, are the major factors underlying organelle genome size expansion.

We compared tandem repeat distribution among red algae (Additional file 1: Fig. S2b) and found that the Porphyridiophyceae has the largest number of mitogenome-encoded tandem repeats. Interestingly, $P$. aerugineum CCMP1948 has the greatest tandem repeat content but the smallest mitogenome among the Porphyridiophyceae. In contrast, $P$. purpureum CCMP1328 has more tandem repeats and larger mitogenomes than P. purpureum SAG1380-1a. To compare the repeat density in each species, we counted the number of repeats per 1,000 bp (Repeat density; Additional file 1: Fig. S2c). The repeat density in Galdieria sulphuraria was 2.05 per $1 \mathrm{kbp}$, which is the highest among all mitogenomes of red algae. The average repeat density of Porphyridium (0.95 repeat $/ \mathrm{kbp}$ ) was smaller than in Cyanidiophyceae (1.23 repeat $/ \mathrm{kbp}$ ), suggesting that the repeats in Porphyridium are concentrated in the large intergenic regions (i.e., P. purpureum CCMP1328: 2.85 repeat/ kbp; P. purpureum SAG13801a: 3.24 repeat/kbp; P. aerugineum CCMP1948: 3.70 repeat/ 
kbp). Additionally, the three Porphyridium taxa contain larger tandem repeats $(2-500 \mathrm{bp})$ than those of 10 bangiophycean species (2-100 bp) and 15 florideophycean taxa (2-300 bp) (Additional file 1: Fig. S2d).

\section{Accumulation of repeats in the large intergenic region}

Analysis of genome similarity using the YASS program [22] shows that the most repeats are located in large intergenic regions (LIRs) (i.e., $23 \mathrm{kbp}, 18 \mathrm{kbp}$, and 12 $\mathrm{kbp}$, in CCMP1328, SAG1380-1a, and CCMP1948, respectively, see Fig. 2a). Mitogenome alignments highlight the repeat-rich LIRs in all three Porphyridium species (Fig. 2b). These tandem repeats range in size from 2 to $500 \mathrm{bp}$. Repeats corresponding to $2-100 \mathrm{bp}$ are the most abundant in rRNA, intergenic, intron, and exon regions in all three species (Additional file 1: Fig. S2a). Tandem repeats $>100 \mathrm{bp}$ in size are distributed primarily in intergenic regions.

Repeats are present in all genomes and are particularly abundant in eukaryotes. They exist in both coding and noncoding regions and show length variation through the addition or deletion of sequences. The replication slippage model, known as copy-choice recombination, accounts for repeat length variation [23]. Replication slippage is generally caused by partial denaturation and displacement processes in a DNA strand, causing mispairing at complementary bases at sites where short tandem repeats exist. In the process of replication or repair of mispairing, insertion or deletion of short repeat units occurs, and as a result, tandem repeats of various lengths are generated [24]. Mutations and rearrangements caused by misalignment during DNA replication are sources of genetic diversity that frequently occur in prokaryotes and eukaryotes. In repetitive DNA sequences, dislocation between the replication strand and its template can occur. Repeat misalignment occurs over a range of lengths, from a few to hundreds of base pairs and generally occurs at sites close to the origin of replication [23, 25-27]; these replication slippages are primarily found near the site of replication origin $[25,28$, 29]. Unusually large LIRs have been found in several plant mitogenomes [30-32], but their origin(s) remain unclear [32].

The cumulative GC skew diagram, calculated as $(\mathrm{G}-\mathrm{C}) /$ $(\mathrm{G}+\mathrm{C})$, can be used to predict the origin of replication and terminus [33]. GC contents of the three Porphyridium mitogenomes (CCMP1328, SAG1380-1a, CCMP1948) were $29.2 \%, 28.9 \%$, and $23.7 \%$, respectively (Fig. $2 a$ ). However, GC contents in the LIR were significantly higher in P. purpureum CCMP1328 (39.6\%) and P. purpureum SAG1380-1a (39.8\%). In contrast, GC content of the LIR (20.6\%) in $P$. aerugineum was lower than the average (23.7\%). All three species have high GC skew in the LIR (Fig. 2c), and cumulative GC skew analysis shows that the slope of these values within the LIR region was the highest in two P. purpureum strains (Fig. 2d). In contrast, P. aerugineum CCMP1948 showed one maximum peak and one minimum peak within the LIR. Interestingly, among the three Porphyridium species, two peaks were identified only in P. aerugineum CCMP1948, suggesting the replication origin and terminus, and the minimum peak corresponding to the replication origin was found in the LIR of this species. From these results, we infer that a large number of repeats in the LIR of $P$. aerugineum CCMP1948 were caused by DNA slippage at the site of origin of DNA replication. In contrast, there were no distinct peaks in the two strains of $P$. purpureum, and the slope of the cumulative GC skew increased markedly in the LIR (GC content is $39.3 \%$ and $39.7 \%$ in CCMP1328 and SAG1380-1a, respectively). The origin of replication in the yeast nuclear genomes is generally a short, intergenic region that contains A/T-rich DNA. In contrast, replication origins in metazoan and plant nuclear genomes are long and G/Crich [34]. In the case of the Arabidopsis thaliana nuclear genome, the region $\pm 0.1 \mathrm{~kb}$ from the replication origin midpoints has a much higher GC content (44.5\%) than other regions (35\%) [35]. Because of a close phylogenetic relationship between $P$. sordidum and $P$. purpureum, and an earlier-divergence of $P$. aerugineum within the genus Porphyridium [36], we suggest that the replication origin of $P$. purpureum is located within the LIR. We could not however detect two peaks in the LIRs using the cumulative GC skew method. Added evidence for our hypothesis is the extended G/C-rich region in the LIR of many plant species [35]. Therefore, we postulate that the two P. purpureum strains are likely to have an analogous repeat expansion caused by DNA slippage at the replication origin, as in P. aerugineum.

\section{The origin and expansion of group II intronic ORFs}

The mitogenomes determined in our study contain multiple intronic ORFs: i.e., 14 in CCMP1328, 14 in SAG1380-1a, and five in P. aerugineum. The intronic ORFs in CCMP1328 and SAG1380-1a are located in the cob (5), cox1 (5), atp9 (1), cox2 (1), nad2 (1), and nad5 (1) genes, whereas the five in $P$. aerugineum are all encoded in $\operatorname{cox} 1$ (Fig. $1 \mathrm{~b}$ and Additional file 2: Table S3). Based on a BLASTx search $\left(e\right.$-value cutoff $\left.=1.0 e^{-5}\right)$ against the NCBI non-redundant database, all Porphyridium intronic ORFs are intron-encoded proteins (IEPs) in group II introns. Group II introns can be classified into several types based on RNA sequence and secondary structure. Alternatively, group II introns can be classified according to phylogenetic analysis of their IEP amino acid sequences. These two classification methods can be used for different purposes. The classification method based on RNA sequence and secondary structure can be applied to all introns regardless of whether 


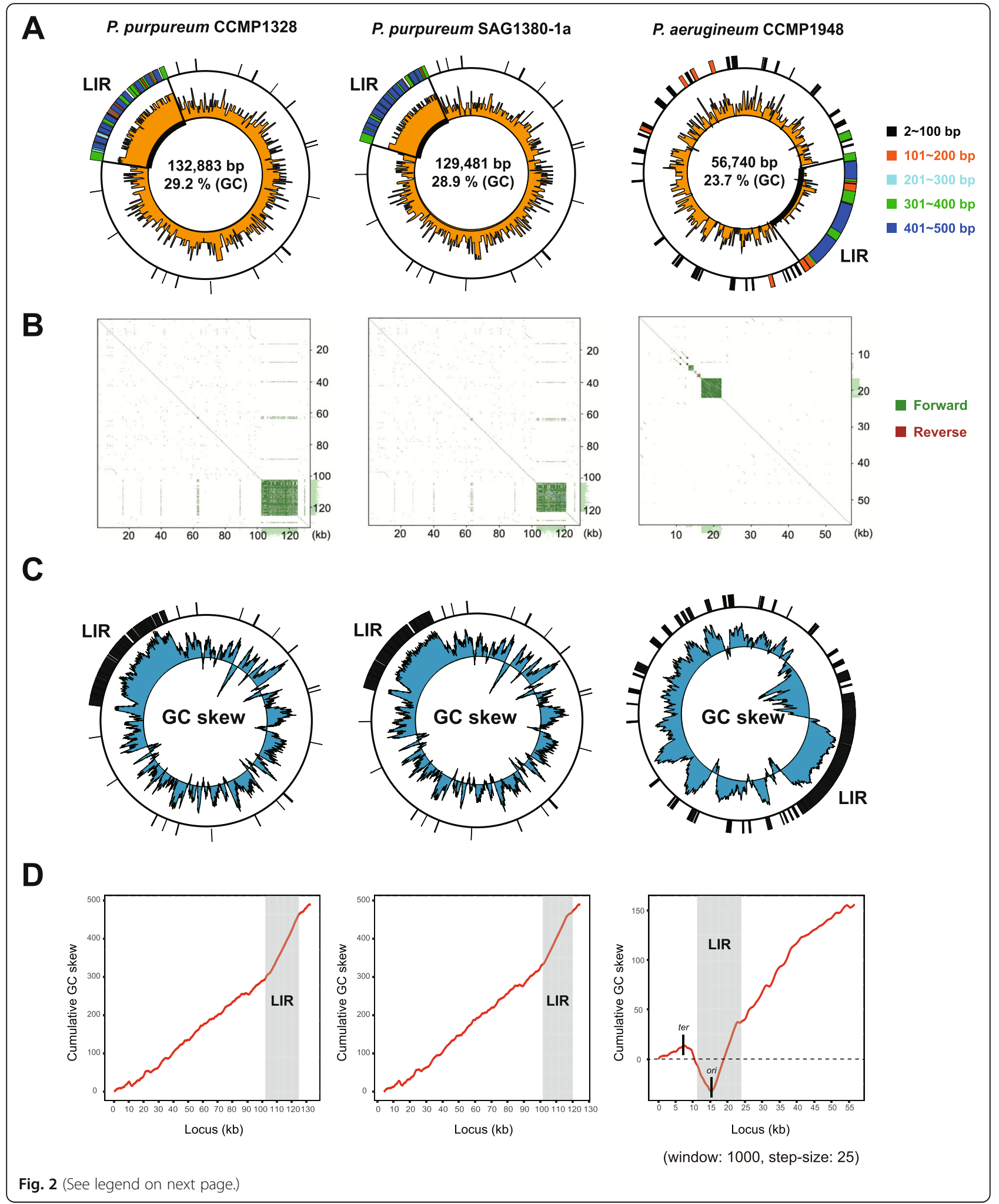


(See figure on previous page.)

Fig. 2 Repeat and GC content analysis of Porphyridium mitogenomes. a The distribution of repeats by length is shown in the outer circle, whereas GC content is shown in the inner circle. LIR is the large intergenic region. $\mathbf{b}$ Three YASS dot-plots generated using self-comparisons. The green segments show alignments of forward reads and red segments show alignments between the reverse complement of one sequence and the forward read of the other. c Three GC skew plots are shown, each obtained from the mitogenome of Porphyridium species with the distribution of tandem repeats ( window size $=1000$, step size $=25$ ). $\mathbf{d}$ Cumulative GC skew plots of the three studied Porphyridium species. Sequence corresponding to the large intergenic region (LIR) is indicated in gray

the group II intron encodes an IEP. In contrast, IEPbased classification is more specific and suitable to describe the origin of group II introns corresponding to particular phylogenetic clades [6]. For this reason, we used IEP-based phylogenetics to determine the origin of group II introns [5]. Particular attention was paid to the relationship between nucleus and organelle-encoded IEPs due to endosymbiotic gene transfer (EGT) between these compartments, or alternatively, acquisition from bacteria or other eukaryotes via horizontal gene transfer (HGT). Amino acid sequences of the 33 IEPs were used as queries to search for homologs $(e$-value cutoff $=1.0 e$ ${ }^{-5}$ ) in the nuclear and plastid genomes of Porphyridium species (PRJNA560054, MF401423.1, unpublished genome data of $P$. purpureum SAG1380-1a and $P$. aerugineum CCMP1948). This analysis identified 26 plastid IEPs, whereas no hits were found in the nuclear genome. Protein similarity network analysis suggests a possible evolutionary link between mitochondrial and plastid IEPs (Additional file 1: Fig. S3a).

To identify putative origins via HGT, we used blast with the 33 mitochondrial and 26 plastid IEPs encoded in Porphyridium group II introns to query the NCBI database (search cutoff, $e$-value $\leq 1.0 e^{-5}$ ). This search returned sequences from 424 taxa including diverse bacteria and eukaryotes (rhodophytes, viridiplants, rhizarians, stramenopiles, cryptophytes, haptophytes, euglenozoids, and fungi). The maximum likelihood tree constructed from these data (Fig. 3a) identified two major clades (PT [plastid including cyanobacteria] and MT [mitochondria including bacteria]) that were likely derived from cyanobacteria and alpha-proteobacteria, respectively. Interestingly, mitochondrion encoded $r n l$ group II IEPs of Bangiophyceae (8/10 reported MTs; Pyropia tenera, $P$. yezoensis (2), P. nitida, $P$. perforate, $P$. haitanensis, Porphyra umbilicalis, Por. purpurea (2), and Bangia fuscopurpurea) and Florideophyceae (i.e., Ahnfeltia plicata) were positioned within the PT clade with cyanobacteria (clade-1 in PT clade). Therefore, group II IEPs may have been transferred from unspecified cyanobacterial donors into the $r n l$ gene of the ancestor of Bangiophyceae, followed by an independent transfer to Ahnfeltia, because only A. plicata contains rnl group II IEPs among 67 reported florideophycean mitogenomes. Because there are no group II IEPs in the plastid genomes of Bangiophyceae and Florideophyceae, it is unlikely to have been transferred between organelles within a cell (i.e., from plastid to mitochondria or vice versa). Because these cyanobacterium-derived mitochondrial group II IEPs in the $r n l$ do not cluster with other red algal plastid group II IEPs, it is unlikely that they were vertically inherited from the early-diverged plastid genomes (i.e., Cyanidiophyceae, Porphyridiophyceae, Compsopogonophyceae, Rhodellophyceae). Evidence for the introduction of group II intronic ORFs from cyanobacteria to mitochondria exists for a red ( $\mathrm{rnl}$ in Porphyra purpurea) [38] and a brown alga ( $r n l$ in Pylaiella littoralis) [39].

Within MT, three distinct clades were found (MT clade-1, -2, and -3). MT clade-1, comprises 30 bacteria (including beta and gamma-proteobacteria), five fungi, one green alga, and five bangiophycean red algae, and is positioned in $\mathrm{rnl}$ genes that differ from cyanobacteriumderived $r n l$ group II IEPs (clade-1 in the PT clade, see above). Although both are located in the same mitochondrial $r n l$, this result suggests that these two types of $r n l$ group II IEPs of the Bangiophyceae have different origins (i.e., independent HGTs from cyanobacteria and proteobacteria, respectively, see Fig. 3b). The MT clade- 3 consists of two early diverged proteobacterial clades and diverse eukaryotes (i.e., red algae, green algae,stramenopiles, haptophytes, cryptophytes, rhizarians, and fungi) and various mitochondrial genes (i.e., cox, cob, nad, atp, $r n l$, and $r n s$ ) (Fig. 3c and Additional file 2: Table S4). Most of the group II IEPs are located in mitochondrial genes in MT clade-3; however, this clade also includes several plastid-encoded group II IEPs (i.e., Bulboplastis apyrenoidosa, Flintiella sangulnaria of Rhodophyta and diverse Euglenozoa species) and nuclear-encoded maturases (13 spp. of Viridiplantae). The presence of alphaproteobacteria in the basal clade of MT clade- 3 suggests that mitochondrial group II IEPs originated from alphaproteobacteria via mitochondrial endosymbiosis and were later transferred to the plastid or nuclear genome.

\section{Horizontal gene transfer from fungi and stramenopiles}

A distinctive feature of the MT clade is the close relationship between sequences from fungi and stramenopiles (purple and orange colors, respectively, in Fig. 3a). For example, clade- $2,-4,-6,-7$, and -8 include fungal group II IEPs found in diverse genes, while clade- $3,-5$, $-6,-7$, and -8 include group II IEPs of stramenopiles, 
A

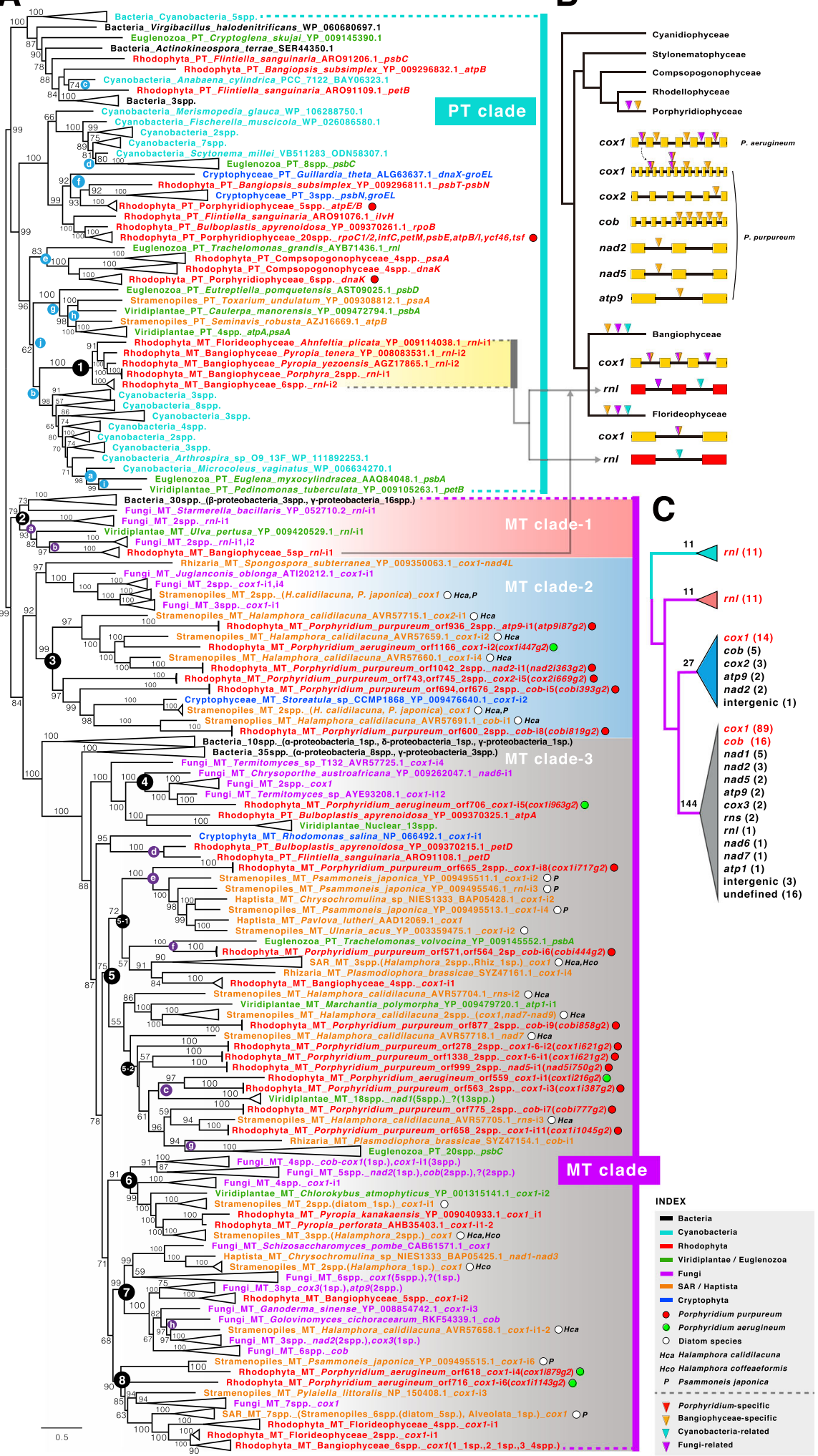

Fig. 3 (See legend on next page.) 
(See figure on previous page.)

Fig. 3 Maximum likelihood phylogeny of group II intron ORFs. a Maximum likelihood tree of group II intronic ORFs was identified using BLASTp (evalue cutoff $=1.0 e^{-5}$ ). The taxa corresponding to red algal mitochondria are marked in red. The taxa corresponding to red algal plastids are marked in blue. Among the red algal taxa, Porphyridium species are marked with a colored circle (P. purpureum MT; red circle, P. aerugineum MT; green circle, Porphyridium PT; red circle). The taxa corresponding to fungi are in purple, cyanobacteria are in cyan, non-cyanobacterial bacteria are in black, non-red algal mitochondria are in orange, and non-red algal plastids are in green text. The clades described in the main text are indicated by black-filled and white-numbered circles. The clades corresponding to the contents in Fig. 5a are presented in colored circles in alphabetical order. The location of the intron (i.e., $r n /-i 1=$ intron 1 in $r n l$ ) is shown after the gene name. We used the previously proposed nomenclature [37] to identify the Porphyridium mitochondrial introns. Bootstrap values below $50 \%$ were removed. b The distribution of red algal mitochondrial group II introns based on the phylogenetic tree. The origins of IEPs present in each intron are shown using triangles of different colors (fungus-related: purple; stramenopiles-related: orange; both-related: mixed with purple and orange). c A simplified tree indicating the number of mitochondrial genes with group II introns based on clades (PT clade and MT clades 1, 2, and 3)

particularly from three diatom species (Psammoneis japonica, Halamphora calidilacuna, and Halamphora coffeaeformis, marked with white dots). Symbiotic relationships between algae and fungi have been reported. A well-known case includes 22 lichen-symbionts in the Trebouxiophyceae [40] and Nanochloropsis oceanica, which are internalized within hyphae of the fungus Mortierella elongata [41]. These symbiotic relationships begin with physical contact between fungal and algal cells, or the exchange of nutrients such as carbon and nitrogen. Both fungi and algae are physiologically active during co-cultivation, and eventually, the photosynthetic algae are internalized and function within fungi. Fungal group II introns can move vertically via the host mitogenome, by a fungal mitochondrial plasmid, or can be transferred horizontally across inter- and intraspecific boundaries [42, 43]. Although there are no existing reports of a symbiotic relationship between Porphyridium and fungi, our phylogenetic analysis (Fig. 3a) shows a close relationship between fungi-Bangiophyceae (clade-2, -7) and fungi-P. aerugineum (clade-4), suggesting intimate contact between these taxa.

In the case of stramenopiles, several diatom species, in particular $P$. japonica and $H$. calidilacuna, are closely related to sequences in Porphyridium species (clade-3, -5, -8) and to the Bangiophyceae and Florideophyceae (clade-6, -8). Mitogenome size in H. calidilacuna is 103 $\mathrm{kb}$, which is the largest among diatom species known to date and includes a large number of group II introns [44]. A study of group II introns in other diatom species shows their transfer between non-diatom (Chattonella, Raphidophyceae) and diatom species $[45,46]$. There are many reports of epiphytic diatoms inhabiting the surface of diverse algae (Rhodophyta, Chlorophyta, and Streptophyta) [47-49], where they exchange various substances such as inorganic nutrients [50]. The driving force of gene transfer between different species can be a plasmid or a virus. Plasmids carry foreign DNA and evidence of these genetic elements have been found in many algae and diatoms [51, 52]. Likewise, viruses can encode a large amount of DNA, and there are reports that HGT occurs in algae and diatoms via a virus [53, 54].
Although there are no reports of a symbiotic relationship between Porphyridium, diatoms, and fungi, our study suggests that HGTs may occur between these lineages.

To understand the interrelationships of group II intronic ORFs, we used the EGN [55] to reconstruct a network of all organisms used in Fig. 3a phylogenetic tree (e-value $\leq 1.0 e^{-5}$, hit identity $\left.\geq 20 \%\right)$. Two nodes were connected by an edge if they shared homologous DNA. The layout was produced by Cytoscape [56], using an edge-weighted spring-embedded model, whereby genomes sharing more DNA families are in closer proximity [57]. The gene network is divided into two subgroups, based on the group II intron of Rhizobium sp. (alpha-proteobacteria), the largest hub node: fungirich cluster (top cluster) and cyanobacteria-rich cluster (bottom cluster). In the fungi-rich cluster, most of the IEPs are located in cox 1 and $c o b$, whereas in the cyanobacteria-rich cluster, most of the IEPs are located in rRNA and $p s a / p s b$ genes. We find that IEPs transfer to specific genes in each organelle. Interestingly, there are many IEPs of Halamphora calidilacuna around these two subgroups and many IEPs of Porphyridium that are only connected to $H$. calidilacuna. Based on this, it can be expected that many IEPs of Porphyridium form a closer relationship with $H$. calidilacuna than with the two subgroups. Additionally, there are several clusters separated from the subgroups ('Viridiplanate_Nuclear', 'Viridiplantae_MT', 'Euglenozoa_PT'), and these clusters are expected to diverge from the biggest hub node due to the accumulation of genetic changes after group II intron transfer. Among them, the cluster of nuclear IEPs in Viridiplantae (i.e., 'Viridiplantae_Nuclear') appears to be a spliceosomal intron that exists in nuclear DNA. Therefore, the close relationship between Porphyridium, $H$. calidilacuna, and fungi is corroborated by the phylogenetic tree shown in Fig. 3a and the gene network (Fig. 4b and Additional file 1: Fig. S3b).

The network shows Termitomyces sp. to be a key species that includes 10 major hubs of group II intron IEPs (Fig. 4b). This fungal species has the largest mitogenome (239 kb, intron size: $51 \mathrm{~kb}$ ), however, total intron size is 


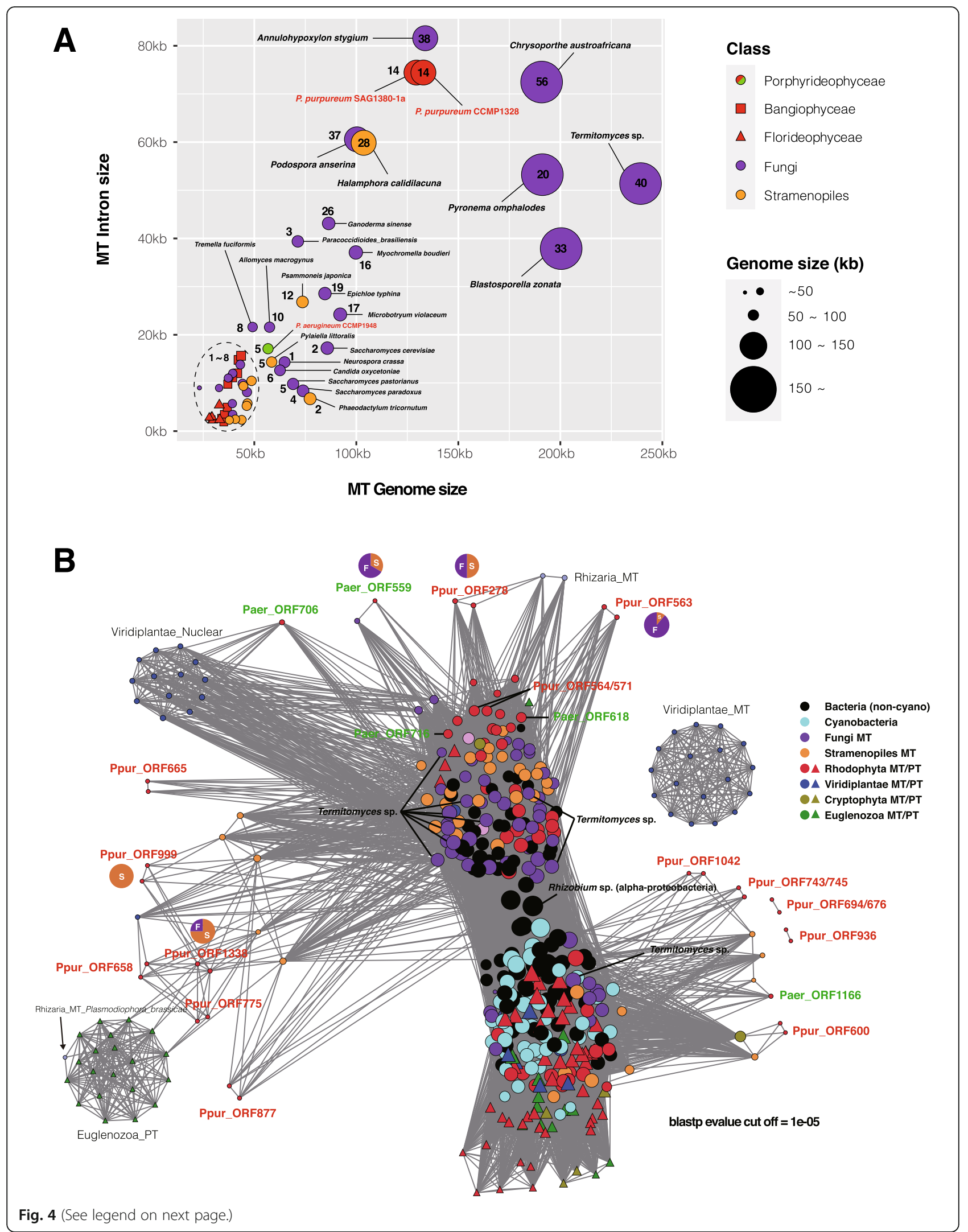


(See figure on previous page.)

Fig. 4 Identification of the major eukaryotic lineages related to Porphyridium mitogenome and group II intronic ORFs done using network analysis. a Dot plot comparing mitogenome size and intron size of species most closely related to Porphyridium mitogenome among the eukaryotes used in Fig. 3a. The number of IEPs is shown inside or next to the circle. $\mathbf{b}$ Protein similarity network of group II IEPs using all of the taxa shown in Fig. 3a, assembled using a BLASTp search (e-value cutoff $\left.=1.0 e^{-5}\right)$. Nodes representing genes with high intramodular connectivity appear larger in the network. Node colors are different for each lineage (see legend)

fifth largest followed by Annulohypoxylon styglum (133 kb, intron size: $81 \mathrm{~kb}$ ), Chrysoporthe austroatricana (190 $\mathrm{kb}$, intron size: $72 \mathrm{~kb})$, Podospora anserina (100 kb, intron size: $60 \mathrm{~kb}$ ) and Pyronema omphalodes (191 kb, intron size: $53 \mathrm{~kb}$ ) (Fig. 4a). In addition, we tested the correlation between total intron length, the number of IEPs, and mitogenome size among the taxa we investigated (Additional file 1: Fig. S1b). These results show that these three factors are moderately correlated with each other, suggesting that larger introns contain a larger number of IEPs. The gene network analysis was used to address the ambiguous topology (clade 5-2 in Fig. 3a) characterized by low bootstrap values (i.e., orf278,

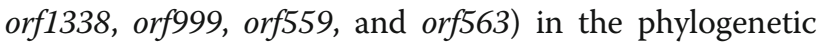
tree. As a result, four IEPs (i.e., orf278, orf1338, orf559, and orf563) except for orf 999 , which have node-edge relationships only with stramenopiles, form node-edge relationships with both fungi and stramenopiles. These results suggest multiple gene transfers from diatom and fungal species (Fig. 4b). This phenomenon has previously been reported [6] from cyanobacteria to Euglena [58], from unknown taxa to cryptophytes [59] or green algae [60], and between diatoms and Chattonella (Raphidophyceae) [45].

\section{Gene-specific vertical inheritance}

Another interesting feature of the MT clade is that mitochondrial group II introns are predominantly encoded in the $\operatorname{cox} 1$ gene (i.e., 103/162 in $\operatorname{cox} 1$, see Fig. 3c and Additional file 2: Table S4). Intron-rich $\operatorname{cox} 1$ genes have been reported in diverse species [61, 62]; therefore, we hypothesized that there may be a target site in $\operatorname{cox} 1$ that is targeted by group II introns, including a conserved splice donor and accepter site (i.e., 5'-GU----AG-3') [63, 64]. To test this idea, we aligned a $10 \mathrm{bp}$ region that is $5^{\prime}$ and 3 'of the intron insertion site, as well as $5 \mathrm{bp}$ of each terminus of the intron sequence for all taxa that were included in Fig. 3a and Porphyridium species only (Additional file 1: Fig. S4). In the intron region, there was a slightly elevated AG signal at the acceptor site (A 38\%, G 48\%) but no GU skewness (G 31\%, T 34\%) in all taxa, whereas in the Porphyridium-only alignment, a higher GU signal (G 42\%, T 42\%) was found at the donor site, but no AG signal at the acceptor site (A 37\%, G 44\%). There were no dominant sequences around splice sites in the $\operatorname{cox} 1$ exon region, presumably due to the AT-rich mitogenome, even though the $5^{\prime}$ site 1 shows a dominant $\mathrm{T}$ (66\%) (Additional file 1: Fig. S4). Rather than having a conserved insertion site, cox 1 , which is the most conserved gene in the mitogenome [65], likely provides a stable target for autocatalytic intron spread in populations and species. From a phylogenetic perspective, orf559 and orf563 in the cox1 gene (clade 5-2, see Fig. 3a) form a well-supported monophyletic clade, suggesting vertical inheritance between $P$. purpureum and $P$. aerugineum (Fig. $3 \mathrm{~b}$ ). In addition to the cox 1 gene, group II IEPs are also present in other genes (Additional file 1: Fig. S3b). Most of the IEPs in the fungus-rich cluster are located in cox 1 and cob, whereas in the cyanobacterium-rich cluster, they are in mitochondrial rRNA and photosystem I and II genes in plastid genomes. These data suggest that IEPs were transferred from alpha-proteobacteria via mitochondrial primary endosymbiosis and targeted $c o x 1$ and $c o b$ genes, whereas IEPs transferred from cyanobacteria and other proteobacteria were inserted in rRNA and photosystem I and II genes.

\section{Self-Proliferation}

Four twintrons (cobi858g2ii2121g2, cox1i387g2ii1392g2, atp9i87g2ii1464g2, cobi444g2ii1128g2) and one twintron (cox1i447g2ii1767g2) were found in the P. purpureum and $P$. aerugineum mitogenomes, respectively (Additional file 1: Fig. S5). Twintrons (introns-within-introns) are rarely reported, but interestingly, the first red algal twintrons were reported from the plastid genome of $P$. purpureum CCMP1328 [18]. Although these twintrons were found in the same strain within the plastid and mitochondrial DNA, they did not share sequence similarity. Instead, mitochondrial twintrons share sequence similarity ( $e$-value $\leq 1 e-10)$ to other introns in mitogenomes. For example, the twintron (cobi858g2ii2121g2) of $P$. purpureum shows high sequence similarity to other twintron (atp9i87g2ii1464g2), intron regions (cobi777g2, cox1i1045g2), and partial intronic ORFs (orf563 in cox1i387g2, orf999 in nad5i750g2), whereas a twintron in orf1166 (cox1i447g2ii1767g2) shows sequence similarity to intron region (cobi441g2) and partial intronic ORF (orf706 in cox1i963g2) (Additional file 1: Fig. S5). Organelle genome twintrons have been reported in the cox1 gene of Lycopodiaceae species [37], as well as in the chloroplast genome of Euglena [66]. These results suggest that some group II introns were duplicated within a mitogenome, resulting in twintrons. 


\section{Conclusions}

This study reports the largest red algal mitochondrial genomes described thus far. The unusual size expansion of Porphyridium mitogenomes is explained by the invasion of group II introns in genic regions and the expansion of repeats in the large intergenic region. Our work makes clear that group II introns are able to transfer across species boundaries. A model that depicts the complex evolutionary trajectory of group II introns is shown in Fig. 5. We find that although the two strains of $P$. purpureum that were studied (i.e., CCMP1328 and SAG1380-1a) contain the same set of introns and IEPs, their genome sizes differ widely (132 kbp vs. $129 \mathrm{kbp}$ ) due to repeat content ( $23 \mathrm{kbp}$ vs. $18 \mathrm{kbp}$, respectively), demonstrating the dynamic nature of red algal mitogenome evolution. Although P. purpureum and P. aerugineum are sister species, the genome size, number of introns (i.e., IEPs), and length of LIRs are substantially different between these taxa (Fig. 1a). In this case, intron expansion in $P$. purpureum (74 kbp) was a major contributor to the genome size difference when compared to $P$. aerugineum (17 kbp of introns), which likely occurred post-speciation. When comparing the two species of Porphyridium, only orf559 and orf563 in cox 1 were likely to have been present in their common ancestor, with the remainder being derived from more recent HGT events or twintron formation (Fig. 1b). As such, the three Porphyridium species provide a model for understanding the forces driving organelle genome expansion and the mobility of group II introns.

Based on our data, we demonstrate three possible scenarios for group II intron spread: gene-specific vertical inheritance, HGT, and self-proliferation (Fig. 5). Because most eukaryotes share group II introns located in a few conserved genes (i.e., cox1, cob, rRNA, and PSI/ PSII subunit genes), it is likely that many have been inherited vertically since the primary endosymbiosis events involving proteobacteria (mitochondrion) and cyanobacteria (plastids). Group II introns in cox1, cob, and some rRNA genes may be derived from alphaproteobacteria, whereas group II introns in PSI/PSII subunit genes and some rRNA genes were derived from cyanobacteria and other bacteria (Fig. 3). The cyanobacterium-derived rRNA introns later invaded the mitochondrial genome (clade-1 in Fig. 3a). Several fungal and diatom species are key players in these mobility events across species/phylum boundaries. In addition, there are gene transfers between organelles (e.g., Bulboplastis apyrenoidosa, Flintiella sangulnaria of Rhodophyta and diverse Euglenozoa) as well as from organelles to the nucleus (some Viridiplantae species, see Additional file 1: Fig. S3b). The large-scale protein similarity-based network analysis of IEPs resolves two connected components, each of which contains plastid and mitochondrion encoded mobility enzymes present in distantly related species. These components are linked by bacterial IEPs. The network results suggest that organelle DNA and bacterial genomes provide "safe harbors" for autocatalytic RNAs that facilitate their spread. These mobile elements are likely continually being purged from extant nuclear genomes due to negative impacts on RNA stability and translation [13].

Although it remains highly challenging to account for the entirety of group II intron origin and evolution, novel genome data such as from Porphyridium, provide a more accurate picture of the dynamic history of these mobile genetic elements. Our work underlines the need to more deeply sample intron-rich clades to reconstruct intron origins and losses rather than comparing these sequences across vast phylogenetic distances with no understanding of the impact of recent evolutionary events. Another consideration that our study points to is the possibility that group II introns are "canaries in the coal mine" for HGTs of non-mobile protein coding genes. If proximity fosters HGT, as is generally accepted, then the patterns of transfer shown here may be useful tools for searching for other HGT events between lineages that share homologous group II introns.

\section{Methods}

\section{Strain information and sample preparation}

Three strains of Porphyridium [Porphyridium purpureum CCMP1328, P. purpureum SAG1380-1a, P. aerugineum CCMP1948] were obtained from culture collections (NCMA, https://ncma.bigelow.org/; SAG, https://www.uni-goettingen.de/). Each strain was subcultured in L1-Si standard medium, modified brackish DY-V medium, and DY-V standard medium [67], respectively.

\section{Genome sequencing, assembly, gene prediction, and annotation}

Cells were harvested by centrifugation $(14,000 \mathrm{rpm}$ for 5 $\mathrm{min})$. Total genomic DNA was extracted using the CTAB method [68]. Total DNA from each species was sequenced using ONT (Oxford Nanopore Technologies, Oxford, England) and Illumina (NovaSeq 6000 system: paired-end TruSeq Nano DNA Prep Kit) platforms. Each sample for ONT sequencing was prepared as following the Nanopore library preparation protocols provided by the manufacturer. The ONT library was constructed by using Ligation Sequencing Kit (SQK-LSK109). This library was sequenced with Ligation Sequencing Kit (SQK-LSK109), Flow Cell Priming Kit (EXPFLP001), and Flow Cell (FLO-MIN106). All runs were performed on the GridION sequencer. We assembled mitochondria genome using the Canu assembler v1.4 [69]. Mitogenome-related contigs were sorted by customized Python scripts with local BLAST programs compared to the 


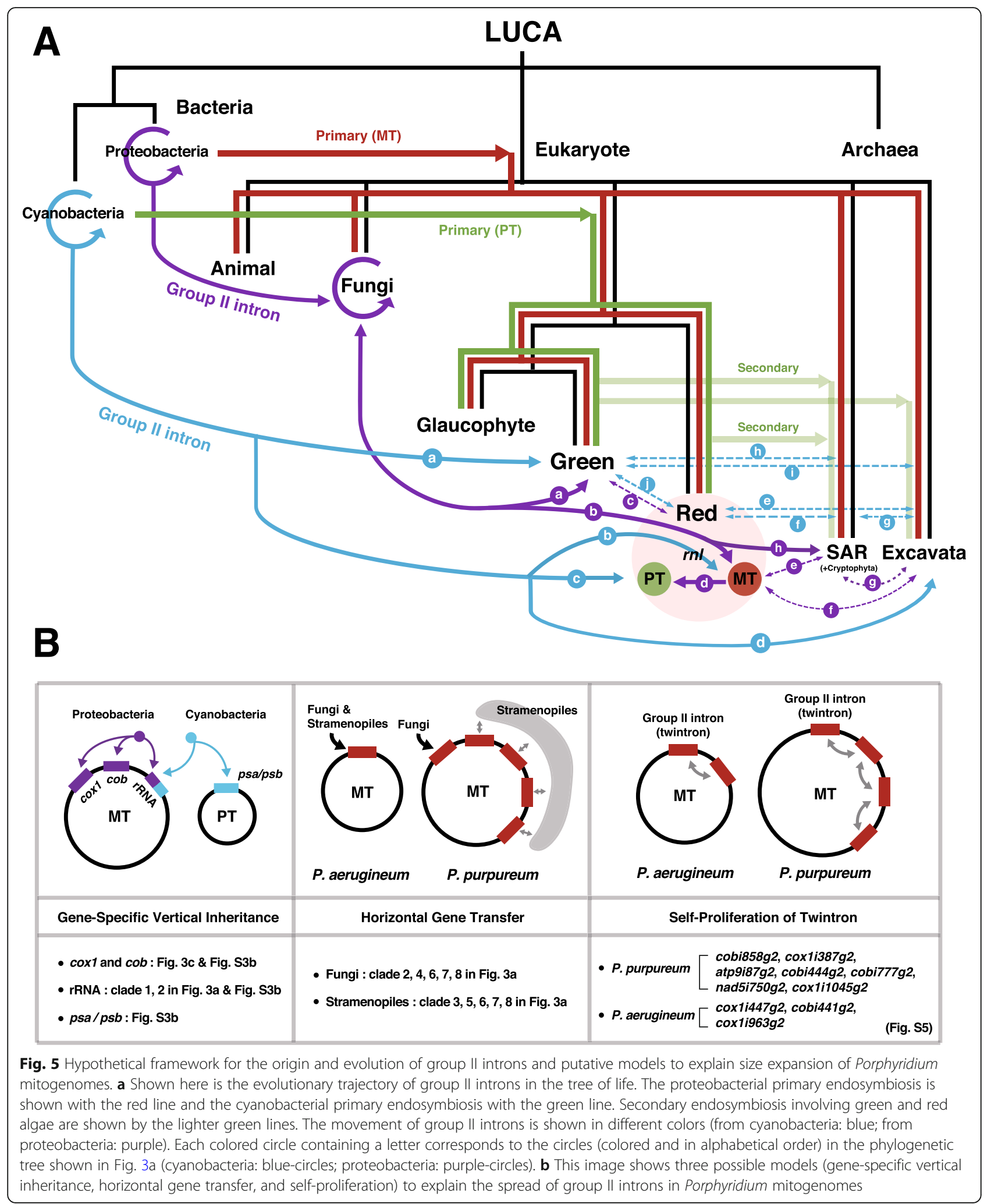

reference genome data (Bangia fuscopurpurea; GenBank accession NC_026905.1), and the sorted contigs were reassembled to construct consensus mitochondrial genomes.
The Illumina data were then mapped against the Canu assembly contigs using CLC Genomics Workbench v8.0.3 (CLC Bio., Aarhus, Denmark) for error correction. 
Gene prediction was carried out with a comparison to the reference gene sequences using BLASTx search $(e-$ value $\leq 1 e-10$ ) and the Geneious 8.1.2 program (Kearse et al. 2012) with translation_table 4 (Mold Protozoan Mitochondrial). To predict tRNA regions, we used ARAGORN [70] using the default option. To predict rRNA regions, RNAmmer 1.2 Server [71] was used. BLASTn search was used to check the rRNA region manually. The twintrons present in the Porphyridium mitogenomes were aligned and compared to other introns using BLASTn to allow identification of outer and inner introns. We used the previously proposed nomenclature [37] to discriminate between the Porphyridium mitochondrial introns. Finally, the mitochondria genome map was visualized with the GenomeVx program [72].

\section{Analysis of repeat sequences in mitochondrial genomes} Repeats were identified by BLASTn, dot-plot comparison in a genomic similarity search tool (YASS) [22], and ETANDEM tool (EMBOSS package) [73]. The input size for searching tandem repeat using ETANDEM tool was divided into 2 100 bp, 101 200 bp, 201 300 bp, 301 400 bp, and $401 \sim 500 \mathrm{bp}$. All the settings of YASS and ETAN DEM were default values.

\section{Gene network and phylogenetic analysis of mitochondrial intronic ORF}

To identify the relationship between organelle intronic ORFs and nuclear genome of Porphyridium purpureum CCMP1328 (NCBI BioProject ID: PRJNA560054, Genome accession number VRMN00000000), all intronic ORFs in the mitochondria and chloroplast genomes of three Porphyridium species were used. To construct phylogenetic trees, homology searches for mitochondrial intronic ORF were conducted against local $\mathrm{nr}$ database using BLASTp ( $e$-value cutoff $=1 \mathrm{e}^{-05}$, word size $=6$ ). The collected homologous genes were aligned using MAFFT v7.313 (default option: --auto) and phylogenetic relationships were inferred with IQ-tree (v1.6.7) (model test: -m TEST and replications: -bb 1000) [74]. To avoid biased taxon sampling, the search criterion used was the maximum number of taxa for each query (i.e., max phylum limitation = top 75 species), thereafter, duplicated taxa were removed. In addition, we removed short sequences (under 175 amino acids) from the phylogenetic analysis, with further filtering by selecting a single representative from each monophyletic clade. The gene network analysis was done using Cytoscape [56] and the EGN program [55].

\section{Abbreviations}

Mitogenome: Mitochondrial genome; LIR: Large intergenic region; IEP: Intronencoded protein; ORF: Open reading frame; snRNA: Small nuclear RNA; LTR: Long terminal repeat; CDS: Coding sequence; EGT: Endosymbiotic gene transfer; HGT: Horizontal gene transfer; MT: Mitochondria; PT: Plastid;
PSI: Photosystem I; PSII: Photosystem II; CTAB: Cetyltrimethylammonium bromide; ONT: Oxford Nanopore Technologies

\section{Supplementary Information}

The online version contains supplementary material available at https://doi. org/10.1186/s12915-021-01200-3.

Additional file 1: Figures S1-S5. Fig. S1. Correlation analysis. (a) Correlation analysis between mitochondria genome size and length of CDS+ORF, intergenic region, and intron. The black dots represent all published red algal mitogenomes in $\mathrm{NCBI}$, whereas colored dots represent three Porphyridium species. (P. purpureum CCMP1328; Red, P. purpureum SAG1380-1a; Yellow, P. aerugineum CCMP1948; Green). Blue lines indicate linear regression line, black dot lines indicate prediction interval, and grey bounds indicates confidence interval with 95\% confidence level. (b) Correlation analysis between mitochondria genome size, length of intron, and number of IEP. Blue lines indicate linear regression line, red dot lines indicate prediction interval, and grey bounds indicates confidence interval with 95\% confidence level. Fig. S2. Repeat distribution of Porphyridium and red algal mitogenome. (a) Frequency of repeats by length in the Porphyridium mitogenome. The cutoff value for tandem repeats was $100 \mathrm{bp}$. (b) Genome size versus the number of repeats in mitogenome among the red algae. (c) Repeat density in the red algae (number of repeat / $1 \mathrm{kbp}$ ). (d) Frequency of repeats by length in the red algal mitogenome. The cutoff value for tandem repeats was $100 \mathrm{bp}$. (e) Information on the taxa used in Figures S2b-d. Fig. S3. Gene network analysis. (a) Similarity network generated from all three Porphyridium mitochondrial ORFs against BLAST similarity search to the plastid and nuclear genome of $P$. purpureum CCMP1328. Each colored node (red, orange, yellow, blue, green, and purple) represents an ORF in three genomes including mitochondria, plastid, and nuclear. Each edge (line) represents a significant HSP (high scoring segment pair) according to $p$ value 1e-0.5. (b) Group II IEPs network analysis using whole data in Figure 3a phylogenetic tree. Gene network of group II IEPs based on BLASTp (evalue $\leq 1.0 e^{-5}$, hit identity $\geq 20 \%$ ). All group II IEPs in Figure 3a phylogenetic tree were used as queries, and the dataset required for gene network was constructed using EGN software. The gene network was produced by Cytoscape using an edge-weighted spring-embedded model. Nodes representing genes with high intramodular connectivity appear larger in the network. The more DNA families a node shares, the closer the distance is. Node colors are displayed differently for each gene. Fig. S4. Intron insertion site analysis in cox 1 gene. Partial sequences of exon and intron near the splice site were aligned to find common features for the intron insertion site of the cox 1 gene. In the exon region, 10 $\mathrm{bp}$ of each $5^{\prime}$ and $3^{\prime}$-end were aligned by MAFFT alignment program. In the case of intron region, $5 \mathrm{bp}$ of each $5^{\prime}$ and $3^{\prime}$-end were aligned. A sequence logo was added to the panel below each alignment to indicate dominant sequences. (a) Results from all taxa and (b) results from Porphyridium-only analysis. Fig. S5. Location of twintrons in Porphyridium mitogenome. Location of twintrons is presented based on the results of BLASTn search and ClustalW alignment. The e-value cutoff is $1 e-10$. In each gene, exons are shown in yellow, introns in white, intronic ORFs in green, and twintrons in gray with dotted lines. Based on the BLASTn results, the areas sharing similarity are shown by connecting them with the red color. The nomenclature of introns and twintrons follows the previously proposed system [37].

Additional file 2: Tables S1-S5. Table S1. Red algal mitogenome information. The genome size, GC content, CDS, ORF, and intron information of red algal mitogenomes published in NCBI are shown in this table. Table S2. Molecular organization of the mitochondrial genes in red algae. The composition of mitochondrial genes of red algal mitogenomes published in NCBI is shown in this table. Table S3. Mitogenome information of Porphyridium species. The length of gene and CDS, number of group II IEPS, and the proportion of introns in each mitochondrial gene of three Porphyridium species are shown in this table. Table S4. Distribution of mitochondrial group II introns in Figure 3. This table shows the number of IEPs in mitochondrial genes in all eukaryotic taxa used in the phylogenetic tree in Figure 3. Table S5. Public dataset 
used in this study. This table shows the GenBank accession numbers and references for the mitogenomes used in this study.

Additional file 3. Alignment file (NEXUS format): Alignment file for Fig 3a (NEXUS format)

\section{Acknowledgements}

The authors thank Louis Graf for the technical support for the correlation test.

\section{Authors' contributions}

D.K., J.L., C.H.C., and E.J.K. did the analysis, AND H.S.Y. and J.L. designed and supervised the study. D.K., D.B., and H.S.Y. wrote the manuscript. All authors read and approved the final manuscript.

\section{Funding}

This work was supported by the Collaborative Genome Program of the Korea Institute of Marine Science and Technology Promotion (KIMST) funded by the Ministry of Oceans and Fisheries (MOF) (20180430) and the National Research Foundation of Korea (NRF-2017R1A2B3001923). DB was supported by a grant from the National Aeronautics and Space Administration (80NSSC19K0462) and a NIFA-USDA Hatch grant (NJ01180).

\section{Availability of data and materials}

The data was deposited in the GenBank under the accession numbers of MT483995 [75] (P. aerugineum CCMP1948), MT483996 [76] (P. purpureum CCMP1328), and MT483997 [77] (P. purpureum SAG1380-1a). All data information used in this study are included in Additional file 2: Table S5. Alignment file used in this study is included in Additional file 3.

\section{Declarations}

\section{Ethics approval and consent to participate}

Not applicable

\section{Consent for publication}

Not applicable

\section{Competing interests}

The authors declare that they have no competing interests.

\section{Author details}

'Department of Biological Sciences, Sungkyunkwan University, Suwon 16419, South Korea. ${ }^{2}$ Department of Oceanography, Kyungpook National University, Daegu 41566, South Korea. ${ }^{3}$ Department of Biochemistry and Microbiology, Rutgers University, New Brunswick, NJ 08901, USA.

\section{Received: 27 June 2021 Accepted: 29 November 2021}

Published online: 07 January 2022

\section{References}

1. Zimmerly S, Hausner G. Wu X-c. Phylogenetic relationships among group II intron ORFs. Nucleic Acids Res. 2001;29(5):1238-50. https://doi.org/10.1093/ nar/29.5.1238

2. Robart A, Zimmerly S. Group II intron retroelements: function and diversity. Cytogenet Genome Res. 2005;110(1-4):589-97. https://doi.org/10.1159/ 000084992.

3. Enyeart PJ, Mohr G, Ellington AD, Lambowitz AM. Biotechnological applications of mobile group II introns and their reverse transcriptases: gene targeting, RNA-seq, and non-coding RNA analysis. Mobile DNA. 2014;5(1):119. https://doi.org/10.1186/1759-8753-5-2.

4. Turmel $\mathrm{M}, \mathrm{Otis} \mathrm{C}$, Lemieux $\mathrm{C}$. The chloroplast and mitochondrial genome sequences of the charophyte Chaetosphaeridium globosum: insights into the timing of the events that restructured organelle DNAs within the green algal lineage that led to land plants. Proc Natl Acad Sci U S A. 2002;99(17): 11275-80. https://doi.org/10.1073/pnas.162203299.

5. Abebe M, Candales MA, Duong A, Hood KS, Li T, Neufeld RA, et al. A pipeline of programs for collecting and analyzing group II intron retroelement sequences from GenBank. Mobile DNA. 2013;4(1):1-9. https:// doi.org/10.1186/1759-8753-4-28.
6. Zimmerly S, Semper C. Evolution of group II introns. Mobile DNA. 2015;6(1): 7. https://doi.org/10.1186/s13100-015-0037-5.

7. Lambowitz AM, Zimmerly S. Group II introns: mobile ribozymes that invade DNA. Cold Spring Harb Perspect Biol. 2011;3(8):a003616. https://doi.org/1 $0.1101 /$ cshperspect.a003616.

8. Guo H, Zimmerly S, Perlman PS, Lambowitz AM. Group II intron endonucleases use both RNA and protein subunits for recognition of specific sequences in double-stranded DNA. EMBO J. 1997;16(22):6835-48. https://doi.org/10.1093/emboj/16.22.6835.

9. Ikuta K, Kawai H, Müller DG, Ohama T. Recurrent invasion of mitochondrial group II introns in specimens of Pylaiella littoralis (brown alga), collected worldwide. Curr Genet. 2008;53(4):207-16. https://doi.org/10.1007/s00294008-0178-X.

10. Toro N. Bacteria and Archaea Group II introns: additional mobile genetic elements in the environment. Environ Microbiol. 2003;5(3):143-51. https:// doi.org/10.1046/j.1462-2920.2003.00398.x.

11. Lambowitz AM, Zimmerly S. Mobile group II introns. Annu Rev Genet. 2004; 38(1):1-35. https://doi.org/10.1146/annurev.genet.38.072902.091600.

12. Toor N, Hausner G, Zimmerly S. Coevolution of group II intron RNA structures with their intron-encoded reverse transcriptases. RNA. 2001;7(8): 1142-52. https://doi.org/10.1017/S1355838201010251.

13. Chalamcharla VR, Curcio MJ, Belfort M. Nuclear expression of a group II intron is consistent with spliceosomal intron ancestry. Genes Dev. 2010; 24(8):827-36. https://doi.org/10.1101/gad.1905010.

14. Tannin-Spitz T, Bergman M, van Moppes D, Grossman S, Arad SM. Antioxidant activity of the polysaccharide of the red microalga Porphyridium sp. J Appl Phycol. 2005;17(3):215-22. https://doi.org/10.1007/s10811-0050679-7.

15. Lee J, Kim D, Bhattacharya D, Yoon HS. Expansion of phycobilisome linker gene families in mesophilic red algae. Nat Commun. 2019;10(1):1-10. https://doi.org/10.1038/s41467-019-12779-1.

16. Bhattacharya D, Price DC, Chan CX, Qiu H, Rose N, Ball S, et al. Genome of the red alga Porphyridium purpureum. Nat Commun. 2013;4(1):1941. https:// doi.org/10.1038/ncomms2931.

17. Tajima N, Sato S, Maruyama F, Kurokawa K, Ohta H, Tabata S, et al. Analysis of the complete plastid genome of the unicellular red alga Porphyridium purpureum. J Plant Res. 2014;127(3):389-97. https://doi.org/10.1007/s10265014-0627-1.

18. Perrineau M-M, Price DC, Mohr G, Bhattacharya D. Recent mobility of plastid encoded group II introns and twintrons in five strains of the unicellular red alga Porphyridium. PeerJ. 2015;3:e1017. https://doi.org/10.7717/peerj.1017.

19. Bi G. Characterization of the complete plastid genome of Porphyridium purpureum strain CCMP1328. Mitochondrial DNA Part B. 2017;2(2):489-90. https://doi.org/10.1080/23802359.2017.1361358.

20. Qiu H, Yoon HS, Bhattacharya D. Red algal phylogenomics provides a robust framework for inferring evolution of key metabolic pathways. PLOS Curr. 2016;8 ecurrents.tol.7b037376e6d84a1 be34af756a4d90846.

21. Turmel M, Otis C, Lemieux C. An unexpectedly large and loosely packed mitochondrial genome in the charophycean green alga Chlorokybus atmophyticus. BMC Genomics. 2007;8(1):137. https://doi.org/10.1186/1471-21 64-8-137.

22. Noé L, Kucherov G. YASS: enhancing the sensitivity of DNA similarity search. Nucleic Acids Res. 2005:33(suppl_2):W540-W3.

23. Viguera E, Canceill D, Ehrlich SD. Replication slippage involves DNA polymerase pausing and dissociation. EMBO J. 2001;20(10):2587-95. https:// doi.org/10.1093/emboj/20.10.2587.

24. Zhou K, Aertsen A, Michiels CW. The role of variable DNA tandem repeats in bacterial adaptation. FEMS Microbiol Rev. 2014;38(1):119-41. https://doi. org/10.1111/1574-6976.12036.

25. Cleary JD, Nichol K, Wang Y-H, Pearson CE. Evidence of cis-acting factors in replication-mediated trinucleotide repeat instability in primate cells. Nat Genet. 2002;31(1):37-46. https://doi.org/10.1038/ng870.

26. Mirkin EV, Mirkin SM. To switch or not to switch: at the origin of repeat expansion disease. Mol Cell. 2014;53(1):1-3. https://doi.org/10.1016/j.molcel.2 013.12.021.

27. Lovett ST. Encoded errors: mutations and rearrangements mediated by misalignment at repetitive DNA sequences. Mol Microbiol. 2004;52(5):124353. https://doi.org/10.1111/j.1365-2958.2004.04076.X.

28. Gerhardt J, Bhalla AD, Butler JS, Puckett JW, Dervan PB, Rosenwaks Z, et al. Stalled DNA replication forks at the endogenous GAA repeats drive repeat 
expansion in Friedreich's ataxia cells. Cell Rep. 2016;16(5):1218-27. https:// doi.org/10.1016/j.celrep.2016.06.075.

29. Kim JC, Harris ST, Dinter T, Shah KA, Mirkin SM. The role of break-induced replication in large-scale expansions of (CAG) $n /(C T G) n$ repeats. Nat Struct Mol Biol. 2017;24(1):55-60. https://doi.org/10.1038/nsmb.3334.

30. Rodríguez-Moreno L, González VM, Benjak A, Martí MC, Puigdomènech P, Aranda MA, et al. Determination of the melon chloroplast and mitochondrial genome sequences reveals that the largest reported mitochondrial genome in plants contains a significant amount of DNA having a nuclear origin. BMC Genomics. 2011;12(1):424. https://doi.org/10.11 86/1471-2164-12-424.

31. Sloan DB, Alverson AJ, Chuckalovcak JP, Wu M, McCauley DE, Palmer JD, et al. Rapid evolution of enormous, multichromosomal genomes in flowering plant mitochondria with exceptionally high mutation rates. PLoS Biol. 2012;10(1):e1001241. https://doi.org/10.1371/journal.pbio.1001241.

32. Mower JP, Sloan DB, Alverson AJ. Plant Mitochondrial Genome Diversity: The Genomics Revolution. In: Wendel J, Greilhuber J, Dolezel J, Leitch I. (eds) Plant Genome Diversity Volume 1. Springer, Vienna. 2012; p.123-144. https://doi.org/10.1007/978-3-7091-1130-7_9

33. Lu J, Salzberg SL. SkewIT: The Skew Index Test for large-scale GC Skew analysis of bacterial genomes. PLoS Comp Biol. 2020;16(12):e1008439. https://doi.org/10.1371/journal.pcbi.1008439.

34. Liachko I, Youngblood RA, Tsui K, Bubb KL, Queitsch C, Raghuraman M, et al. GC-rich DNA elements enable replication origin activity in the methylotrophic yeast Pichia pastoris. PLoS Genet. 2014;10(3):e1004169. https://doi.org/10.1371/journal.pgen.1004169.

35. Costas C, de la Paz SM, Stroud H, Yu Y, Oliveros JC, Feng S, et al. Genomewide mapping of Arabidopsis thaliana origins of DNA replication and their associated epigenetic marks. Nat Struct Mol Biol. 2011;18(3):395-400. https:// doi.org/10.1038/nsmb.1988.

36. Efimova K, Kreshchenovskaya M, Aizdaicher N, Orlova TY. A genetic and ultrastructural study of three clones of Porphyridium purpureum (Bory de Saint-Vincent, 1797) Drew et Ross, 1965 (Rhodophyta) from the marine microalgae collection of the Zhirmunsky institute of marine biology. Russian J Marine Biol. 2014;40(5):364-74. https://doi.org/10.1134/S1063074014 050022.

37. Zumkeller S, Gerke P, Knoop V. A functional twintron,'zombie'twintrons and a hypermobile group II intron invading itself in plant mitochondria. Nucleic Acids Res. 2020;48(5):2661-75. https://doi.org/10.1093/nar/gkz1194.

38. Burger G, Saint-Louis D, Gray MW, Lang BF. Complete sequence of the mitochondrial DNA of the red alga Porphyra purpurea: cyanobacterial introns and shared ancestry of red and green algae. Plant Cell. 1999;11(9): 1675-94. https://doi.org/10.1105/tpc.11.9.1675.

39. Fontaine J, Rousvoal S, Leblanc C, Kloareg B, Loiseaux-de GS. The Mitochondrial LSU rDNA of the brown alga Pylaiella littoralis reveals aProteobacterial features and is split by four group IIB introns with an atypical phylogeny. J Mol Biol. 1995;251(3):378-89. https://doi.org/10.1006/ jmbi.1995.0441.

40. Muggia L, Leavitt S, Barreno E. The hidden diversity of lichenised Trebouxiophyceae (Chlorophyta). Phycologia. 2018;57(5):503-24. https://doi. org/10.2216/17-134.1.

41. Du Z-Y, Zienkiewicz K, Pol NV, Ostrom NE, Benning C, Bonito GM. Algalfungal symbiosis leads to photosynthetic mycelium. Elife. 2019;8:e47815. https://doi.org/10.7554/eLife.47815.

42. Qu G, Piazza CL, Smith D, Belfort M. Group II intron inhibits conjugative relaxase expression in bacteria by mRNA targeting. Elife. 2018;7:e34268. https://doi.org/10.7554/eLife.34268.

43. Bock R. The give-and-take of DNA: horizontal gene transfer in plants. Trends Plant Sci. 2010;15(1):11-22. https://doi.org/10.1016/j.tplants.2009.10.001.

44. Pogoda CS, Keepers KG, Hamsher SE, Stepanek JG, Kane NC, Kociolek JP. Comparative analysis of the mitochondrial genomes of six newly sequenced diatoms reveals group II introns in the barcoding region of cox1. Mitochondrial DNA Part A. 2019;30(1):43-51. https://doi.org/10.1080/247013 94.2018.1450397

45. Kamikawa R, Masuda I, Demura M, Oyama K, Yoshimatsu S, Kawachi M, et al. Mitochondrial group II introns in the raphidophycean flagellate Chattonella spp. suggest a diatom-to-Chattonella lateral group II intron transfer. Protist. 2009;160(3):364-75. https://doi.org/10.1016/j.protis.2009.02.003.

46. Guillory WX, Onyshchenko A, Ruck EC, Parks M, Nakov T, Wickett NJ, et al. Recurrent loss, horizontal transfer, and the obscure origins of mitochondrial introns in diatoms (Bacillariophyta). Genome Biol Evol. 2018;10(6):1504-15. https://doi.org/10.1093/gbe/evy103.

47. Car A, Witkowski A, Dobosz S, Jasprica N, Ljubimir S, Zgłobicka I. Epiphytic diatom assemblages on invasive Caulerpa taxifolia and autochthonous Halimeda tuna and Padina sp. seaweeds in the Adriatic Sea-summer/ autumn aspect. Oceanol Hydrobiol Stud. 2019;48(3):209-26. https://doi.org/1 0.2478/ohs-2019-0019.

48. Siqueiros Beltrones DA, Martínez YJ. Prospective floristics of epiphytic diatoms on Rhodophyta from the Southern Gulf of Mexico. Cicimar Ocean. 2017;32(2):35-49. https://doi.org/10.37543/oceanides.v32i2.207.

49. Chung M-H, Lee K-S. Species composition of the epiphytic diatoms on the leaf tissues of three Zostera species distributed on the southern coast of Korea. Algae. 2008;23(1):75-81. https://doi.org/10.4490/ALGAE.2008.23.1.075.

50. Mutinová PT, Neustupa J, Bevilacqua S, Terlizzi A. Host specificity of epiphytic diatom (Bacillariophyceae) and desmid (Desmidiales) communities. Aquat Ecol. 2016;50(4):697-709. https://doi.org/10.1007/s104 52-016-9587-y.

51. Lee J, Kim KM, Yang EC, Miller KA, Boo SM, Bhattacharya D, et al. Reconstructing the complex evolutionary history of mobile plasmids in red algal genomes. Sci Rep. 2016;6(1):23744. https://doi.org/10.1038/srep23744.

52. Ruck EC, Nakov T, Jansen RK, Theriot EC, Alverson AJ. Serial gene losses and foreign DNA underlie size and sequence variation in the plastid genomes of diatoms. Genome Biol Evol. 2014;6(3):644-54. https:/doi.org/10.1093/gbe/evu039.

53. Van Etten J, Graves M, Müller D, Boland W, Delaroque N. Phycodnaviridaelarge DNA algal viruses. Arch Virol. 2002;147(8):1479-516. https://doi.org/1 0.1007/s00705-002-0822-6.

54. Short SM. The ecology of viruses that infect eukaryotic algae. Environ Microbiol. 2012;14(9):2253-71. https://doi.org/10.1111/j.1462-2920.2012.02706.x.

55. Halary S, McInerney JO, Lopez P, Bapteste E. EGN: a wizard for construction of gene and genome similarity networks. BMC Ecol Evol. 2013;13(1):1-9.

56. Saito R, Smoot ME, Ono K, Ruscheinski J, Wang P-L, Lotia S, et al. A travel guide to Cytoscape plugins. Nat Methods. 2012;9(11):1069-76. https://doi. org/10.1038/nmeth.2212.

57. Halary S, Leigh JW, Cheaib B, Lopez P, Bapteste E. Network analyses structure genetic diversity in independent genetic worlds. Proc Nat Acad Sci U S A. 2010;107(1):127-32. https://doi.org/10.1073/pnas.0908978107.

58. Sheveleva EV, Hallick RB. Recent horizontal intron transfer to a chloroplast genome. Nucleic Acids Res. 2004;32(2):803-10. https://doi.org/10.1093/nar/ gkh225.

59. Khan $\mathrm{H}$, Archibald JM. Lateral transfer of introns in the cryptophyte plastid genome. Nucleic Acids Res. 2008;36(9):3043-53. https://doi.org/10.1093/nar/ gkn095.

60. Odom OW, Shenkenberg DL, Garcia JA, Herrin DL. A horizontally acquired group II intron in the chloroplast psbA gene of a psychrophilic Chlamydomonas: in vitro self-splicing and genetic evidence for maturase activity. RNA. 2004;10(7):1097-107. https://doi.org/10.1261/rna.7140604.

61. Vallès $Y$, Halanych KM, Boore JL. Group II introns break new boundaries: presence in a bilaterian's genome. PLoS One. 2008;3(1):e1488. https://doi. org/10.1371/journal.pone.0001488.

62. Ehara M, Watanabe Kl, Ohama T. Distribution of cognates of group II introns detected in mitochondrial cox 1 genes of a diatom and a haptophyte. Gene. 2000;256(1-2):157-67. https://doi.org/10.1016/S0378-1119(00)00359-0.

63. Du H, Rosbash M. The U1 snRNP protein U1C recognizes the $5^{\prime}$ splice site in the absence of base pairing. Nature. 2002;419(6902):86-90. https://doi.org/1 0.1038 /nature00947.

64. Carmel I, Tal S, Vig I, Ast G. Comparative analysis detects dependencies among the 5' splice-site positions. RNA. 2004;10(5):828-40. https://doi.org/1 $0.1261 /$ rna.5196404

65. Castellana S, Vicario S, Saccone C. Evolutionary patterns of the mitochondrial genome in Metazoa: exploring the role of mutation and selection in mitochondrial protein-coding genes. Genome Biol Evol. 2011;3: 1067-79. https://doi.org/10.1093/gbe/evr040.

66. Thompson MD, Copertino DW, Thompson E, Favreau MR, Hallick RB. Evidence for the late origin of introns in chloroplast genes from an evolutionary analysis of the genus Euglena. Nucleic Acids Res. 1995;23(23): 4745-52. https://doi.org/10.1093/nar/23.23.4745.

67. Andersen R, Morton S, Sexton J. Provasoli-Guillard National Center for Culture of Marine Phytoplankton. J Phycol. 1997;33(s6):1-75. https://doi. org/10.1111/j.0022-3646.1997.00001.x.

68. Prasad B, Lein W, Lindenberger CP, Buchholz R, Vadakedath N. Stable nuclear transformation of rhodophyte species Porphyridium purpureum: 
advanced molecular tools and an optimized method. Photosynth Res. 2019; 140(2):173-88. https://doi.org/10.1007/s11120-018-0587-8.

69. Koren S, Walenz BP, Berlin K, Miller JR, Bergman NH, Phillippy AM. Canu: scalable and accurate long-read assembly via adaptive k-mer weighting and repeat separation. Genome Res. 2017;27(5):722-36. https://doi.org/10.1101/ gr.215087.116.

70. Laslett D, Canback B. ARAGORN, a program to detect tRNA genes and tmRNA genes in nucleotide sequences. Nucleic Acids Res. 2004;32(1):11-6. https://doi.org/10.1093/nar/gkh152.

71. Lagesen K, Hallin P, Rødland EA, Stærfeldt H-H, Rognes T, Ussery DW. RNAmmer: consistent and rapid annotation of ribosomal RNA genes. Nucleic Acids Res. 2007;35(9):3100-8. https://doi.org/10.1093/nar/gkm160.

72. Conant GC, Wolfe KH. GenomeVx: simple web-based creation of editable circular chromosome maps. Bioinformatics. 2008;24(6):861-2. https://doi. org/10.1093/bioinformatics/btm598.

73. Rice P, Longden I, Bleasby A. EMBOSS: the European molecular biology open software suite. Trends Genet. 2000;16(6):276-7. https://doi.org/10.101 6/S0168-9525(00)02024-2.

74. Nguyen L-T, Schmidt HA, von Haeseler A, Minh BQ. IQ-TREE: a fast and effective stochastic algorithm for estimating maximum-likelihood phylogenies. Mol Biol Evol. 2014;32(1):268-74. https://doi.org/10.1093/ molbev/msu300. Accessed 27 May 2021

75. Kim D, Lee J-M, Cho CH, Kim EJ, Bhattacharya D, Yoon HS. Mitochondrial genome assembly and annotation of Porphyridium (Porphyridium aerugineum CCMP1948) 2021. https://www.ncbi.nlm.nih.gov/nuccore/MT483 995. Accessed 28 Nov 2021.

76. Kim D, Lee J-M, Cho CH, Kim EJ, Bhattacharya D, Yoon HS. Mitochondrial genome assembly and annotation of Porphyridium (Porphyridium purpureum CCMP1328) 2021. https:/www.ncbi.nlm.nih.gov/nuccore/MT483996. Accessed 28 Nov 2021.

77. Kim D, Lee J-M, Cho CH, Kim EJ, Bhattacharya D, Yoon HS. Mitochondrial genome assembly and annotation of Porphyridium (Porphyridium purpureum SAG1380-1a) 2021. https://www.ncbi.nlm.nih.gov/nuccore/MT483997. Accessed 28 Nov 2021.

\section{Publisher's Note}

Springer Nature remains neutral with regard to jurisdictional claims in published maps and institutional affiliations.

Ready to submit your research? Choose BMC and benefit from:

- fast, convenient online submission

- thorough peer review by experienced researchers in your field

- rapid publication on acceptance

- support for research data, including large and complex data types

- gold Open Access which fosters wider collaboration and increased citations

- maximum visibility for your research: over $100 \mathrm{M}$ website views per year

At $\mathrm{BMC}$, research is always in progress.

Learn more biomedcentral.com/submissions 